\title{
LA NARRATIVA HUMORÍSTICA DE UN NOVELISTA SERIO: ANTONIO MINGOTE
}

José María Ferri Coll Universidad de Alicante

La ingente y laureada labor de Mingote como dibujante ha hecho que su obra literaria permanezca en un segundo plano de su producción artística. Dibujos y novelas comparten, no obstante, el mismo humor del que el autor ha hecho gala en los chistes y caricaturas publicados en libros, revistas y periódicos desde los tiempos de La cabra hasta la actualidad. Aunque han pasado ya casi sesenta años desde la publicación de su primera novela, Mingote, explorando diversos subgéneros siempre en clave humorística -fantástico, policíaco, western, realismo decimonónico, etc.--, se ha valido del humor del absurdo y de la técnica de la greguería de Gómez de la Serna para armar sus novelas. La razón de que este tipo de humor cale con fuerza en el lector radica fundamentalmente en la ternura con que Mingote trata a sus personajes, característica que se ha mantenido incólume desde su primer relato. Esa humanización del humor, idea brillantemente expuesta por Bergson - «Il n'y a pas de comique en dehors de ce qui est proprement humain> [1984: 388]-, se opone a los postulados de un arte deshumanizado. Las criaturas de Mingote, ya dibujadas, ya descritas en una novela, despiertan en el lector una profunda ternura, tal vez por su ingenuidad o acaso por actuar como lo haría un niño. Pero vayamos al principio.

Un año antes de que Antonio Mingote debutara como novelista con un asombroso libro, Las palmeras de cartón (1948), Emilio González López afirmaba que la novela era el signo literario de la España de aquellos momentos. Ese mismo año de la publicación del relato de Mingote, que 
Entrambasaguas reseñó considerándolo la mejor novela de 1948 [Villanueva Nieto, 2002: 59], y del que Jorge Campos destacó en Punto su «sentimiento lírico» [1949], se habían presentado ciento veintidós obras al ya prestigioso Premio Nadal, que había iniciado su andadura cuatro años antes; por el mismo tiempo, José Luis Vázquez Dodero hablaba de un segundo renacimiento de la novela española, hechos todos y palabras que prueban el auge del género en aquellos días. Pero ¿qué novelas se leían en la España de entonces y qué pautas estéticas dominaban el panorama narrativo de un país recién nacido a la pax franquista? ${ }^{1}$ La década del 40 había empezado a ofrecer al lector español cierta diversidad en el panorama novelístico, a pesar de que las editoriales de aquel tiempo se empeñaran en publicar traducciones de novelas extranjeras de diferentes autores -tales como Baring, Bromfield, etc.--, debido a la rentabilidad económica que les reportaban esas obras. Los cuatro éxitos editoriales españoles, según el autorizado parecer de Martínez Cachero [1979b: 120], fueron las novelas de Cela, La familia de Pascual Duarte (1942), de Ignacio Agustí Mariona Rebull (1944), de Carmen Laforet Nada (1945), y de Darío Fernández Flórez Lola, espejo oscuro (1950). Aunque una mayoría considerable de novelistas españoles de aquellos años se consagró al cultivo del relato realista, no se puede obviar la existencia de otras tendencias narrativas. Los novelistas considerados como referente del realismo fueron fundamentalmente Baroja, quien todavía vivía y seguía escribiendo, y a mayor distancia Galdós. En 1942, sorprendió a la crítica la esplendente obra de un escritor novel: La familia de Pascual Duarte, de Cela, a la que siguieron dos años más tarde Pabellón de reposo y Nuevas andanzas y desventuras del Lazarillo de Tormes; en 1946 presentó La colmena a la censura, que la rechazó, por lo que hubo de esperar a su publicación en Buenos Aires cinco años más tarde. Pero, sin duda, el estímulo mayor para los jóvenes novelistas de entonces fue el advenimiento del Premio Eugenio Nadal, que se falló por vez primera a principios de 1945 a favor de la opera prima de una jovencísima Carmen Laforet, que solo aquel año conoció tres ediciones. Nada compitió con otras veinticinco novelas que se presen-

1. El lector interesado en seguir el rastro de la novelística española de la década del 40 puede acogerse a los trabajos específicos de Martínez Cachero [1945, 1979a, y muy especialmente 1983], F. Ynduráin [1952], Baquero Goyanes [1955], y Castellet [1963]. Para el caso de Las palmeras de cartón, véanse los artículos de Martínez Cachero [1983] y García Fuentes [1995]; la reseña del resto de la obra literaria y artística de Mingote, puede verse en el libro de Villanueva Nieto [2002]. En monografias sobre la narrativa del siglo $\mathrm{xx}$, véanse también las páginas que se indican a continuación de los trabajos de Martínez Cachero [1979b: 120 y ss. y 1997: 151-160], Amorós [1979: 151], y Soldevilla [2001: I, 250-262] principalmente. 
taron al certamen. Repárese en el crecimiento considerable de obras que concurrían convocatoria tras convocatoria hasta llegar a los ciento veinte originales de 1950. Entre los ganadores del Nadal destacan escritores de la talla de Gironella, autor del best-seller Los cipreses creen en Dios (1953), y Delibes, que publicó La sombra del ciprés es alargada en el mismo año en que Mingote hizo lo propio con Las palmeras de cartón. También en 1948 vieron la luz las novelas de Manuel Sánchez Camargo Nosotros, los muertos, y de Ana María Matute Los Abel.

En los títulos mencionados se aprecia la impronta del llamado tremendismo, exacerbación de la realidad rayana en lo patológico. Si esta tendencia estética se afanó en presentar aquellos aspectos más deleznables de la condición humana sin reparar en el daño que tal muestra podía causar en la sensibilidad del lector, el humor del absurdo se centró a veces en las conductas y los hábitos grotescos de los personajes descritos censurándolos y caricaturizándolos para convertirlos en casos ridículos objeto de la sonrisa. Pero en ambos casos subyace muchas veces una reflexión sobre la sociedad en que viven el novelista y sus lectores, atendiendo a la infelicidad a que permanecen condenados muchos seres. La misma desdicha, aunque de origen bien diferente, gravita sobre Pascual Duarte que sobre Froilán del Pirineo, el protagonista de Las palmeras de cartón. Ambos son seres que se han dejado llevar por sus instintos, ajenos a los convencionalismos sociales, y por esa razón han sido aislados del cuerpo social. Es la misma infelicidad que convirtió a Gregor Samsa en una cucaracha, en el universal relato de Kafka. En palabras de Ramón Gómez de la Serna, «la actitud más cierta ante la efimeridad de la vida es el humor. Es el deber racional más indispensable» [1931: 199].

No parece justo, por tanto, atribuir a los humoristas del grupo del 27 un desđén hacia los problemas sociales y la realidad histórica de España ${ }^{2}$. Es posible que estos creadores no participaran de la ilusión que invade al autor de literatura comprometida de que su pluma está al servicio de una causa noble y de que su obra acabará siendo un arma eficaz contra la injusticia y la opresión. Despojados de la servidumbre de esta militancia combativa, estos artistas se sirvieron del cine, el teatro, el dibujo, la novela y cuantos medios de expresión estaban a su alcance para levantar la voz

2. Desde el discurso de ingreso en la Real Academia Española pronunciado por López Rubio [1983], se viene usando el año 1927 como seña de identidad del grupo de humoristas contemporáneos a los poetas que comparecieron en Sevilla al homenaje tributado a Góngora en aquel año. Véanse los trabajos de M. L. Burguera Nadal y S. Fortuño [1988], J. M. Torrijos [1989] y González-Grano de Oro [2004]. 
no en nombre de nadie ni para defender ningún ideal, sino pro domo sua con la esperanza de que el lector inteligente comprendiera la intención y alcance de su humor. Dionisio, el mayordomo de Froilán del Pirineo, protagonista de Las palmeras de cartón, cuando recibe la noticia por boca de su señor de que éste se ha arruinado, afirma: «Si el señor lo permite, compartiremos la ruina» [1948: 15]. Aparte de la ternura que despierta el criado fiel, se observa en el comportamiento de éste un derroche de bondad hacia quien ha despilfarrado su patrimonio alegremente. Visto desde fuera se aprecia que frente al egoísmo de Froilán, despunta la generosidad de Dionisio. Ninguno de estos personajes obedece a una clave ni representa a un colectivo social. Cada lector puede identificarse con el personaje que le resulte más cercano a su propia condición y carácter. Incluso tiene la potestad de odiar a Froilán o admirar al ejemplar Dionisio, pero ni uno ni otro, ni su creador, se han propuesto cambiar el mundo.

La «labor bienhechora» del humor de la que habla Mingote [1998: 158] se refiere a la lucha contra cualquier clase de consigna y tópico. Tras haber perdido todo su dinero y haber deshonrado el nombre de su familia, el lector esperaría de Froilán una respuesta heroica, que no podía ser otra que el suicidio. Así Froilán se dispone a quitarse la vida en el rompeolas, pero le falta valor: «Me quité el sombrero y lo tiré al agua. Fue como un suicidio pequeñito» [1948: 11]. Y destinada al lector avezado en suicidios apunta en seguida esta aclaración: «Un suicidio a pistola siempre resulta más distinguido» [1948: 13]. Frente a estos lugares comunes se propone al lector la infinita libertad para reírse de lo que parece serio y pensarse dos veces lo que se vende bajo apariencia de humorada. Para quienes admiran ¡Bienvenido, Mr. Marshall! (1953), en cuyo guión participó Miguel Mihura, sobran los comentarios ${ }^{3}$. Al ver la película en la actualidad nos reímos precisamente de lo que los censores de la época consideraban serio y apropiado. Y tal opinión constituye la lección que Mingote traslada al lector a menudo: lo que es en verdad para morirse de risa es aquello que nos empeñamos en convertir en algo serio y sacralizado, indiscutible. En este sentido, La Codorniz se convirtió, al estrenarse la década del 40, en un espacio destinado a ridiculizar la cursilería y cutrez bajo cuyo manto transcurría la vida del español medio. En nuestros días se debe atender más al valor artístico de aquellos humoristas que a su adscripción política. Con razón, Mingote ha reivindicado el papel que desempeñó La Codorniz en la España de los primeros años de la posguerra:

3. Léase ahora el escrupuloso trabajo de J. A. Ríos [2005], donde se da cuenta, a partir de la película de Berlanga, de la reacción de los humoristas del 27, y más específicamente de Mihura, ante el advenimiento de la dictadura franquista. 
Yo pido que la aparición de La Codorniz en 1941 sea reconocida como lo que fue: un Acontecimiento Histórico Trascendental [sic]. Acontecimiento histórico es aquel que influye en la historia de un país. La aparición de La Codorniz conformó la mentalidad de una generación recién salida de una guerra civil que, sin la beneficiosa influencia de la revista, que abrió ventanas a la esperanza en el porvenir, a la ilusión en seguir viviendo a pesar de la miseria, la marginación y la intransigencia ambiental, no sé en qué abismos de oscurantismo y resentimiento habría podido caer [1998: 151].

Aparte del tremendismo, o mejor dicho, a su lado, aparecen otras obras de índole evasiva como La isla sin aurora (1944) de Azorín, o humorística como las novelas de Jacinto Miquelarena Don Adolfo el libertino (1940), de inspiración ramoniana, cuyo humor radica en lo insólito y ridículo, pero siempre acompañado de una profunda ternura; de Claudio de la Torre Alicia al pie de los laureles (1940); de José María Álvarez Blázquez En el pueblo hay caras nuevas (1945), obra finalista del Nadal en el año en que lo ganó Carmen Laforet, deudora del humor de Wenceslao Fernández Flórez que consigue mantener en vilo al lector hasta el final; y el libro ganador del Nadal La luna ha entrado en casa (1945), de José Félix Tapia. Por aquellos mismos años cobró nombradía el hoy olvidado Zunzunegui, a quien la Academia galardonó con el Fastenrath en 1943 por su novela ;Ay...estos hijos! En 1948 otra obra suya fue distinguida con el Premio Nacional de Literatura. Se trata de La úlcera, novela de humor en que don Lucas, el protagonista, muere aburrido y desocupado, una vez que se le ha curado la úlcera que él había cuidado durante años dedicándole buena parte de su tiempo. La narrativa humorística del 40 siguió de cerca el rastro de Ramón Gómez de la Serna, quien había publicado en 1947 los Cuentos de fin de año, en la misma colección, «El lagarto al sol», donde saldría al año siguiente la novela de Mingote; y un año más tarde su Automoribundia, relato de corte autobiográfico en que se plasma el pesimismo del autor, que constata la fatalidad del destino humano con una sonrisa pesimista ${ }^{4}$. Dos años antes, Edgar Neville había dado a la imprenta $L a$ familia Minguez, compilación de colaboraciones suyas en La Codorniz en las que satiriza a la anodina clase media urbana de la posguerra con displicencia aristocrática. El balance de la producción novelística de la década del 40 resulta satisfactorio, a pesar de todos los obstáculos que la guerra, el exilio y la censura habían ido poniendo en su camino. En cuanto a la

4. Recuérdese el artículo de E. Neville [1955] cuyo título resume sin engaño el influjo de Ramón en el grupo de humoristas del 27: «Ramón, el buque nodriza». 
narrativa humorística del periodo creo que deben recordarse las palabras de Martínez Cachero:

No osaría yo calificar a estos narradores españoles de la década de los 40 como «desorientados» o «distraídos» en el cultivo del humor, tal como ha hecho un docto colega en el tema [se refiere a Gonzalo Soberano, 1975: 44]. Diré, por el contrario, que su oriente fue otro que el de los novelistas a vueltas por entonces con la guerra civil o con los casos patológicos del tremendismo [...]. Fueron una tendencia más en un momento no demasiado rico en variantes, lo cual ya es mérito para que no los olvidemos ni menospreciemos [1983: 346].

A la creación literaria humorística de aquellos años hay que sumar los textos teóricos que sobre el asunto se prodigaron hasta que apareció, en 1951, el Manifiesto del humorismo del novelista cántabro Antonio Botín Polanco (1898-1956), amigo de Gómez de la Serna -quien en 1930 había publicado un interesante artículo sobre sus ideas acerca del humor en la influyente Revista de Occidente-, que venía a cerrar una serie de ensayos que intentaron delimitar el territorio del humor ${ }^{5}$. Así las cosas, cuando el 14 de mayo de 1945, la Academia puso a Wenceslao Fernández Flórez [1979] en el brete de pronunciar su discurso de ingreso en esta insigne institución, el novelista gallego se aplicó en definir el concepto de humor y su presencia en la literatura española. El autor de El malvado Carabel (1931) llegó a la conclusión de que «el humor es, sencillamente, una posición ante la vida» [1979: 27], en plena concordancia con el parecer de Ramón Gómez de la Serna: «Casi no se trata de un género literario, sino de un género de vida, o mejor dicho, de una actitud ante la vida» [1930]. Y como anillo al dedo viene esta postura para abordar la obra narrativa de Antonio Mingote, quien ha expresado su particular reflexión sobre la sociedad en que vive tanto en sus dibujos como en sus relatos. Aunque muchos lectores se acercan a la literatura humorística convencidos de que ha sido escrita solo para hacerles reír, no pienso que Mingote escriba tanto para provocar la risa, como para hacer pensar. En ese sentido, me parece que su obra se puede enmarcar en ese humor que triunfó en España en las décadas inmediatamente posteriores al fin de la Guerra Civil, cuyos representantes más señalados fueron Mihura, Tono y Jardiel. En el fondo, esta

5. Véase para el análisis de las poéticas del humor en el siglo xx el artículo de J. A. Llera [2001]. De esos años datan dos traducciones al español del clásico ensayo de Bergson sobre lo cómico: la que la editorial Losada publicó en Buenos Aires en 1943, y la que vio la luz en Valencia en 1950 bajo el sello de Prometeo. Años después se publicó el trabajo de Acevedo [1966], que viene a demostrar cierta revitalización de los estudios sobre el humor. 
literatura humorística se pone al servicio de una idea de crítica de aquellos aspectos de la sociedad contemporánea que estos escritores consideraban deleznables. Lo dijo con propiedad Mihura:

También es posible que los críticos jóvenes estén en lo cierto y yo me vaya aburguesando y haciéndome viejo. Es lógico. Son los años. Pero no tan viejo y tan burgués como para dejar de luchar como siempre he luchado -desde la prensa, el cinematógrafo y el teatro-contra el eterno tópico, contra la retórica, contra el lugar común, venga de un bando o de otro bando [...] [1989: 43-44].

El elemento caracterizador del nuevo humor es el absurdo, que no es sinónimo de ilógico. Más bien se profundiza, llegando al extremo, en las incongruencias sociales más frecuentes mostrando su incoherencia y falta de motivación racional. Se insiste en los tópicos cursis y lastres de las costumbres que encarcelan a los españoles argumentando a favor de las bondades de la libertad individual y del derecho de cada ser humano a elegir la forma en que quiere vivir y a decidir la manera de existencia que le hace feliz. En ese sentido, lo absurdo intenta desmontar el valor de lo convencional y destacar lo ridículo de unas costumbres que se transmiten de generación en generación sin ningún espíritu crítico o principio racional. Por esa razón, lo absurdo no es ilógico sino extraño a los usos sociales oficiales. Sirva como ejemplo la primera y mejor novela de Mingote, Las palmeras de cartón. El lector va descubriendo poco a poco el sentido de los acontecimientos desde que al principio de la novela se nos presenta a Froilán arruinado, momento en que aparece en su vida Isla, una mujer misteriosa bajo especie alegórica de isla, que resulta haberse evadido de una institución psiquiátrica y que es albergada en casa de Froilán. La recién llegada a la vida de Froilán es, por sus actos y pensamiento, diametralmente opuesta a su novia, Luisa, quien se ajusta a las mil maravillas al canon tradicional de la esposa apropiada para Froilán. Paradójicamente, el héroe recibe una recompensa cuando debería haber padecido un castigo por su conducta inapropiada. Como se aprecia, lo ilógico desaparece del relato porque el comportamiento de Isla se explica por su estado psíquico, del que la medicina puede dar cuenta. Desposeída de cualquier prejuicio social, Isla lleva al absurdo todas las convenciones del mundo en que vive Froilán. En una ocasión, cuando se sientan a la mesa para comer, Isla pregunta a Froilán por qué no se sienta con ellos el mayordomo, Dionisio. Esta situación aparentemente puede provocar la risa del lector, que conoce las pautas que ordenan las relaciones entre señores y sirvientes, pero leído el pasaje con más detenimiento, se llega a la conclusión de que Mingote está subrayando la hipocresía de una sociedad católica que desoye el 
mensaje evangélico de igualdad entre los hombres. En otro momento de la novela, Froilán no ve sino una ducha al observar lo que Isla considera la lluvia [1948: 54]. Y al contemplar el Retiro madrileño, Isla se compadece de los árboles «ahí encerrados» [1948: 90]. Al igual que en el Quijote poco a poco Sancho se va contagiando de las fantasías de su señor, en la obra de Mingote ocurre lo propio, y tras instalarse Isla en casa de Froilán, «Dionisio empezaba a familiarizarse con lo maravilloso» [1948: 79], y Froilán ignoraba «dónde empezaba lo real y dónde lo imaginado» [1948: 99]. Para que no decaiga el asombro del lector, Mingote idea un desenlace ingenioso para la novela. Froilán se entera por su tío de que todo el dinero que ha ido perdiendo en el juego, ha sido ingresado puntualmente en su cuenta bancaria, pero ignora hasta el final de la novela que su mayordomo ha sido el responsable de reponer el dinero. ¿Puede haber una ironía mayor?

La primera novela de Mingote apareció, según lo que se ha dicho arriba, en un momento en que el género goza del interés del público y en que nuevos escritores, Cela y Laforet por dar dos nombres, y recién creados premios literarios, caso del Nadal, despuntan en el panorama editorial español. Heredero del humor de Ramón Gómez de la Serna, y perito en el estilo codornicesco que tan buenos resultados le había dado en compañía de Mihura, Tono, Neville, Jardiel Poncela, López Rubio, y otros tantos, Mingote estaba suficientemente preparado para emprender la tarea de escribir una novela. Al igual que sus compañeros de viaje, es un autor polifacético que se sirve de diferentes formatos para transmitir sus ideas, con claro predominio de la imagen y la caricatura. Porque si el cine sedujo a Neville y a Mihura, el dibujo hizo lo propio con Mingote, de quien no solo leemos sus novelas, sino que casi podemos imaginarlas dibujadas. En este sentido, Las palmeras de cartón se convierte en una obra donde el sentido de la vista prevalece sobre el resto, de suerte que el lector que conozca cómo se las gasta Mingote con el lápiz, puede leer la novela viéndola dibujada. La obra se inicia in medias res. El narrador, Froilán del Pirineo, reduce a sus elementos básicos el relato de los acontecimientos, igual que si se tratara de un dibujo:

Frente a mí, mi adversario dijo sencillamente:

-Escalera de color...

$Y$ así con la misma sencillez con que aquellas tres mágicas palabras fueron pronunciadas, yo, Froilán del Pirineo, quedé arruinado [1948:9].

Este procedimiento esquemático se aprecia en toda la novela. Mingote tiende a presentarnos a los personajes y las situaciones reduciéndolas a sus líneas maestras eludiendo siempre la digresión y el relato de lo accesorio. En el ejemplo que he copiado arriba se observa que el autor se zafa de ofrecer al lector cualquier esbozo biográfico del «adversario», no apa- 
rece ni una sola descripción del lugar, ni hay una mínima digresión acerca del sentido de la acción. Todo se explica atendiendo a sus elementos principales, igual que en un dibujo. Para que el lector perciba la caricatura, en ocasiones animaliza algunos rasgos del personaje, por ejemplo la lotera que cacarea [1948: 126] . En el mismo sentido cobra especial importancia la proporción. Se observa cierta obsesión absurda por precisar tamaños y cantidades sin que el conocimiento de esos datos resulte provechoso para el lector. Léanse algunos ejemplos entre otros tantos:

Luisa recuperó el sentido a la altura del kilómetro catorce, aproximadamente [1948: 66].

Las siete mujeres la miraron con catorce ojos asombrados [1948: 132].

Vi la desilusión claramente reflejada en siete rostros arrugados [1948: 135].

El gran acierto de la novela radica en que mantiene al lector en suspensión durante toda la lectura sorprendiéndolo a menudo con hechos inesperados. Si en el estilo del humor del absurdo y las frases ingeniosas, casi greguerías a veces, recuerda la obra a la creación de Gómez de la Serna, en el tono misterioso y la dimensión sobrenatural de algunos pasajes se acerca más a los relatos de Fernández Flórez. La introducción de un personaje misterioso, Isla, que ve el mundo con los ojos vírgenes de quien vive al margen de las convenciones sociales, resulta especialmente provechoso al autor para dinamitar los tópicos y la cursilería de la sociedad burguesa bienpensante. A pesar de que Froilán «procuraba explicarle lo que veían [...], ella transformaba las cosas, otorgándoles una segunda e imprevista naturaleza» [1948: 92]. Así, al acudir a un baile de alto copete acompañando a Froilán, se pregunta la protagonista «si ellos bailan aquí, ¿qué hacen en sus casas?» [1948:73], en alusión clara a la vida monótona de la burguesía. Se sorprende Isla de «que no guarden las cosas alegres para hacerlas en sus casas» [1948: 73], obligando al narrador a apostillar:

La triste vida de aquellos pobrecitos, que en la pista bailaban desenfrenadamente, puso en la cara de Isla un velo de melancolía que yo intenté borrar, dándole a beber champán y hablándole de nuestras palmeras y de las playas, donde los dos vivíamos, tan lejos de todas aquellas calamidades [1948: 73]. 
La novia de Froilán, Luisa, está en las antípodas de Isla. E1 triángulo recuerda la historia de Dionisio y Paula en Tres sombreros de copa. Mingote, que derrocha ternura en la confección del personaje de Isla, lleva al extremo los defectos de Luisa convirtiéndola en un personaje frívolo que solo busca un casamiento provechoso. Especialmente conseguidos resultan los pasajes de la novela en que Luisa, despechada por el desdén de Froilán hacia ella, intenta darle celos con un torero, ocasión que el narrador aprovecha para lanzar un dardo contra la fiesta nacional como exponente de una españolada rancia: «Yo encendí un cigarrillo para demostrarle que tanto la fiesta nacional como los sentimientos de sus protagonistas no alcanzaban a despertar mi interés en absoluto» [1948: 64].

Igual que en Tres sombreros de copa Mihura se había servido de buenas dosis de lirismo para la caracterización de Paula, lo propio hace Mingote en la descripción del mundo de Isla desde su primera aparición, rodeada de luz en medio de la noche:

Apareció y vino hacia mí como una luz que se acerca, como la brisa que empieza a soplar, como algo inaprensible y fatal. Apenas vi sus grandes ojos verdes, alucinados, comprendí que intentar detener aquella mujer sería tan inútil como poner obstáculos a una aparición [1948: 18].

Consciente el narrador de que se adentra en una descripción literaria, avisa al lector de que no caerá «en la debilidad de decir que eran unas melenas de oro» [1948: 19]. La metáfora del cabello = oro, por manida, no casaría bien con la estética del absurdo en que está inmersa la novela. El universo de Isla se asemeja al mundo bucólico recreado por la literatura clásica: «Yo soy tu isla. Mis playas tienen la arena de oro fresco. Mis palmeras dan sombra para ti. Descansa» [1948: 21].

Nótese que en esta ocasión Mingote echa mano de la metáfora del oro, pero sustituyendo a la arena, imagen menos transitada que la anterior. Isla va creando poco a poco un mundo a su medida, hasta el punto de que Froilán se pregunta: «¿Qué clase de criatura es ésta, capaz de inventar una vida nueva alrededor de unos pedazos de cartón?» [1948: 179]. Se refiere el narrador a la afición que Isla tenía de recortar las palmeras procedentes de seis acuarelas de Bowldy, pintadas en seis cartones, que adornaban con lujo la biblioteca de Froilán. Algo de autobiográfico tiene el pasaje. En una entrevista periodística preguntaron en cierta ocasión a Mingote a qué jugaba de pequeño, y éste contestó: «Mi juego preferido era hacer teatros de cartón y dibujar decoraciones» [en Villanueva Nieto, 2002: 11]. Ese mundo de la infancia de Mingote y del personaje de su novela acaba salpicando la realidad en una suerte de continuum entre lo real y lo maravilloso: «Las palmeras de cartón proyectaron su sombra sobre el pasado y 
sobre el porvenir. No hubo mueble de mi casa ni rincón de mi alma donde no lucieran su gracia bienhechora»s [1948: 110-111].

Tras Las palmeras de cartón, Mingote realizó una breve incursión en la novela policíaca sirviéndose del pseudónimo de Anthony Mask, bajo el cual publicó Ojos de esmeralda [1949], obra de sentido y factura muy diferentes de la anterior. A los pocos años, Joaquín Calvo-Sotelo le encargó un libro para la colección «La Novela del Sábado», en donde se publicó Los revólveres hablan de sus cosas [1953], ejemplo de la devoción de Mingote hacia el western, que triunfaba en las pantallas del cine y en las novelas de Marcial Lafuente Estefanía y de Alf Man [Alfredo Manzano], habiéndose creado una saga de personajes, escenarios y tópicos que se repetían hasta la saciedad y el agotamiento del género. Si en Las palmeras de cartón triunfaba el modelo del humor del absurdo aderezado con notas de ternura y lirismo, en Los revólveres... despunta la parodia, no exenta de toques muy codornicescos, en que el autor elige como falsilla los lugares comunes del género ${ }^{7}$. No falta alguna reflexión metaliteraria sobre el abuso del tópico: «Cualquier habitante de Boston sabía que a los héroes del Oeste se les suele encontrar corrientemente en el cuarto de la muchacha más atractiva de la ciudad. Por lo tanto, Teddy subió al cuarto de Dixie con la naturalidad de quien acude a ocupar su puesto lógico» [2004: 44]. También el tipo de narrador ha cambiado: la primera persona de Las palmeras... deja paso ahora a un narrador omnisciente exógeno que va relatando los hechos al lector. Si en la descripción del personaje y el espacio en Las palmeras... se hallan ecos de la técnica de los dibujos del propio Mingote, en Los revólveres... las influencias cinematográficas son evidentes. Mingote, no obstante, persevera en su voluntad de mantener al lector en suspensión hasta el final ocultándole información fundamental para la inteligencia del argumento de la novela. El forastero Teddy Gallipot llega en diligencia a Morsua City, un pequeño pueblo del Oeste, enviado por su madre para vengar una afrenta familiar que había ocurrido años atrás, pero Teddy averigua que las cosas no ocurrieron como su madre le había contado, sino más bien al contrario: su padre había perdido la mina de oro jugando al póquer, pero no como imaginaba su hijo, sino

7. Parecen sacadas de las páginas de La Codorniz ocurrencias como éstas: «Al sheriff sólo se le pueden dar bofetadas a horas de oficina» [2004: 59]; la creación del personaje del vice-matón [2004: 68]; el sheriff, «instalado en la antesala de la cárcel, se había aplicado con tanto entusiasmo a la lectura de estos periódicos, que en pocos años aprendió a leer» [2004: 78]; «Un piel-roja, convertido en piel-verde por obra del mareo se cayó del caballo matándose en el acto» [2004: 88]; «Los caballos, desnudos, seguían dando vueltas y vueltas y vueltas como locos, en espera de que el jefe tomara una decisión» [2004: 87]; etc. 
porque sus rivales, que se apiadaron de lo mal jugador que era, hacían trampas para dejarlo ganar, hasta que el padre de Teddy los sorprendió y los obligó a que se quedaran con su mina de oro como compensación. Conviene ahora repasar algunos de los tópicos más célebres del western parodiados por Mingote. Como era de esperar, el autor pergeñó a sus personajes agrupándolos en dos polos que representan el bien y el mal. A la cabeza del primero aparece, por supuesto, el protagonista, Teddy, y representando al segundo, Rocky Sullivan, de quien se dice: «Rocky se había consagrado definitivamente. De vez en vez despachaba a un tipo para conservar su prestigio, y los muchachos procuraban no mezclarse en sus asuntos» [2004: 37]. Para completar el elenco era necesario incluir a una chica, Dixie, que es la más guapa del pueblo y canta en el saloon, acompañada por un pianista, «dame tu mano, rudo muchacho de las vacas...», a un sheriff, Tom Risco, que había sido designado para el cargo por ser el único habitante de Morsua City que tenía chaleco, y a unos desaliñados pistoleros de poca monta entre los que se cuenta Wit Wolf, al que llaman «Uve doble Uve doble para abreviar» [2004: 20]. También los espacios aparecen perfectamente acotados: el Gibbous Camel Saloon, cuyo cantinero es Mostacho Joe, el hotel, que en realidad solo se había construido porque todos los pueblos del oeste contaban con uno, y la oficina del sheriff. También el inicio y el final de la novela han sido extraídos de la enciclopedia del western. El forastero, que ha cumplido su misión, se marcha:

Larguirucho Teddy se aleja, caminando, por la pradera. El recuerdo de sus hazañas no morirá nunca en el Oeste. Ya está lejos. Apenas es un punto en la verde lejanía. Y ese punto minúsculo es todo lo que queda de Larguirucho Teddy. Porque aquel, el hombre que va pisando la hierba, allá lejos, no es más que Gallipot; simplemente, Teddy Gallipot, de Boston [2004: 96-97].

El pasaje recuerda a muchos finales de películas del género, algunas míticas como Raices profundas (1953), basada en la novela homónima de Jack Schaefer, y dirigida por George Stevens; o Centauros del desierto (1956), de John Ford, protagonizada por John Wayne. La clausura de la novela afianza la circularidad del relato, motivo que ya había empleado en Las palmeras de cartón. Isla desaparece adentrándose voluntariamente en el mar, mientras que Teddy hace lo propio volviendo al Este. Diríase que Mingote ha querido colocar a estos dos personajes fuera de su entorno para que observen la realidad con los ojos del advenedizo. Como en la vida misma, en el remate de las novelas de Mingote queda algún cabo 
suelto, una brizna de misterio que envuelve la situación haciéndonos creer que nos hemos perdido algo, que nos perderemos algo definitivamente.

Tras Los revólveres..., Mingote abandonó la novela hasta 1991, año en que publicó Adelita en su desván. El autor vuelve a conjugar el humor con elementos fantásticos, ayuntamiento que tan buenos resultados le había dado en Las palmeras de cartón. En su nueva novela, caricaturiza una sociedad provinciana llena de prejuicios y temores. Saca, asimismo, buen partido a los diálogos, ágiles y agudos, entre la galería de personajes que andan por el relato constituyendo una sociedad organizada en grupos que se reúnen para charlar en ambientadas tertulias de cafés y casinos. Si la acción de Las palmeras... se circunscribía fundamentalmente al mundo de la pareja protagonista, en este caso el novelista ha ido construyendo círculos concéntricos en torno a Adelita. El primero estaría formado por el extraño conde que, echando mano de la transformación como elemento mágico, vive bajo aspecto de rana. Después aparece la familia de Adelita; y finalmente se dibuja la sociedad de Torrelonga. De la misma forma que se había planteado en Las palmeras..., Mingote crea un triángulo amoroso en que dos mujeres, Adelita y su tía Hortensia, se enamoran del mismo hombre, el conde. Entre las mujeres, la diferencia radica igual que en su primera novela, en su diferente grado de aceptación de las convenciones sociales. Adelita, joven e inexperta, está preocupada por mantener su virginidad, mientras que Hortensia vive al margen de cualquier presión social, y satisface sus deseos sexuales sin resquemor, aunque finja ante su sobrina haberse echado en brazos del conde para que el honor de la joven no fuera mancillado: «Si es absolutamente necesario que dé usted suelta a sus brutales instintos reprimidos, ¡aquí me tiene a mí! ¡Pero respete a mi inocente sobrina!» [1991: 119].

Todo había empezado cuando Adelita González de la Pineda, cuyo enamorado, Anselmo Encinas, registrador de la propiedad, que se casaría más tarde con ella aceptando la paternidad del niño cuyo padre biológico era el conde Roberto de Peñanegra, encontró en el estanque del jardín de su casa a dicho aristócrata metamorfoseado en una rana desde 1348 [1991: 13]. Recobrada su figura humana, fue alojado por Adelita en el desván de la casa, espacio interior ajeno a la sociedad donde deja de existir la convención y la norma. En Las palmeras..., la casa de Froilán desempeña la misma función. Se hace hincapié, por tanto, en señalar el contraste entre el mundo interior, que actúa como útero protector, y el exterior. La literatura de todos los tiempos está llena de esos espacios míticos donde el orden social se anula a favor de la libertad del individuo. El relato en esta ocasión se inicia siguiendo el patrón clásico: un narrador externo, cuya identidad real averigua el lector al final de la novela, sitúa al lector en el 
lugar, Torrelonga, y el tiempo, el verano de 1909. Cuenta la historia el hijo del conde y Adelita, Roberto Encinas y González de la Pineda, «en homenaje a su padre, Roberto, conde de Peñanegra (1297-1909) y de su larguísimo infortunio»' [1991: 214]. Aunque el sentido de la obra es bien distinto, la construcción de la trama sigue la falsilla de la novela decimonónica realista, incluso la presencia del nombre de la protagonista en el título recuerda los rótulos de grandes éxitos como Doña Luz, Juanita la larga, Pepita Jiménez, La Regenta, etc. La tía de Adelita leía con fruición los cuentos de Pardo Bazán, al tiempo que en el relato se introducen narraciones en primera persona sacadas del diario de Adelita. Se trataba, en definitiva, de acomodar el relato al género que más se leía en España a principios de siglo.

$\mathrm{Al}$ igual que en Las palmeras..., Mingote elige una aparición sorprendente en el arranque de la obra, cuya presencia provocará un cambio radical en la vida del protagonista. Adelita se enamoró del conde y con él perdió su virginidad, hecho que Mingote lleva al absurdo porque las reglas del mundo fantástico del relato obligan a Roberto, una vez que deja de ser rana, a entregar un anillo que porta una piedra giratoria a una joven pura, quien a partir de ese momento será la única que pueda volver a cambiar su estado. Desgraciadamente, Adelita, al perder su virginidad, nunca más pudo dar forma humana a su amado. La joven vive con su rijosa tía Hortensia y con su padre, quien dedica más tiempo a contemplar su flamante Panhard Levassor amarillo que a cuidar de su hija. Convive con la presencia de elementos mágicos el humor codornicesco de toda la narrativa de Mingote, o si no repárese en afirmaciones como ésta: «Por aquellos años, cuando alguien escuchaba una cosa insólita no daba crédito a sus oídos» [1991: 13], o diálogos como el que copio abajo:

$-¿$ Qué es eso, hija?

-¿Qué, papá?

-Eso que llevas en las manos.

-Es una rana, papá.

-¿Por qué?

-Porque también sus padres lo eran [1991: 48].

Asimismo en esta novela se arremete contra la cursilería y el encorsetamiento moral en que se halla constreñida la sociedad descrita por el autor. Adelita tiene que besar a la rana, como todo el mundo sabe, para deshacer el hechizo, pero la joven, muy escrupulosa, pone reparos, por lo que el conde la tranquiliza informándole de que su acto va a ser totalmente puro:

-No soy un hombre...todavía, Adelita. Soy un anfibio. Ni el más riguroso moralista puede reprochar a una señorita que bese a un anfibio.[...] Puedes darme un beso sin quedar mancillada en absoluto [1991: 18]. 
El humor del absurdo se sirve en ocasiones de la hipérbole para transmitir la idea de una realidad desproporcionada. Mingote, al describir la sociedad de principios de siglo xx, se fija en los detalles, usando una vez más la técnica del esquematismo y la reducción de lo observado a sus líneas principales, que pueden, por exageradas, caricaturizarla. Así las cosas, el novedoso automóvil que va acabando con la tranquilidad de la gente de entonces, es objeto de chiste. A la admiración que causó en el padre de Adelita se enfrenta la animadversión que ha suscitado en otros habitantes de Torrelonga, hasta el punto de relatar el suceso siguiente: «-A una prima de mi madre la atropelló en San Sebastián un automóvil conducido por uno de esos monstruos y todavía no se han encontrado sus restos. Fue peor que una bomba» [1991: 59]. O de aludir a uno de los dramaturgos más prestigiosos a principios de siglo: «-A propósito de eso [se está hablando del final de las guerras carlistas] ha dicho Jacinto Benavente que cada cincuenta corridas de toros, por lo menos, suponen un desgaste tal de ferocidad de los españoles que hace imposible una guerra civil» [1991: 63].

Tampoco se desecha la oportunidad de arremeter contra la institución del matrimonio, a la que tan buen partido le había sacado su amigo Mihura, haciendo buenas las palabras de Bergson de que «les cérémonies sont au corps social ce que le vêtement est au corps individuel: elles doivent leur gravité à ce qu'elles s'identifient pour nous avec l'objet sérieux auquel l'usage les attache, elles perdent cette gravité dès que notre imagination les en isole» [1984: 408]:

Hortensia permanecía soltera por honradez. Había descubierto, siendo aún muy joven, que los hombres casados le daban mucha risa. ¿Cómo podría casarse sabiendo que en cuanto el hombre a quien amaba se convirtiera en su marido sería un hombre casado tan cómico como todos los hombres casados que conocía? [1991: 76].

La amiga de Adelita, Carlotita, que ha tenido un affaire con el conde «por pura curiosidad intelectual» [1991: 158], recuerda a éste que tal relación tendrá consecuencias negativas para su futuro matrimonio con «un hombre de posición» porque «los hombres de mi clase - dice- no ven con buenos ojos que sus esposas no lleguen al matrimonio intactas» [1991: 156-157]. Después de la transformación definitiva del conde en rana, Adelita escribió en su diario:

Me ha contado Carlotita que ya está muy tranquila que Juan Manuel Espinoso le quiso coger una mano ayer por la tarde al salir de la novena y ella se enfadó mucho y le dijo a una señorita no se le coge la mano qué se ha creído [...] [1991: 197]. 
Se nota en ocasiones el prurito historicista de Mingote, quien ha dado su particular lectura de los acontecimientos históricos en títulos como Historia de la gente (1955) o Historia de Madrid (1961). Al presentar la modernidad que conlleva la presencia del automóvil en los caminos españoles, no puede obviar el autor que la sociedad española no ha progresado tanto como la tecnología extranjera. Echa mano para demostrarlo de las diversiones de los españoles, que no han cambiado mucho de las que llegaron a horrorizar a Jovellanos siglos atrás. Cuando se están preparando las fiestas de la patrona de la localidad, se pueden escuchar algunas propuestas del aire de las que siguen:

$-¿$ No han pensado ustedes en un partido de foot-ball? -sugirió Manolo-. Es un sport que gusta.

- ¿Más que el novillo ensogado?

-iHombre, son cosas distintas! El foot-ball es un sport inglés que está teniendo éxito. Lo del novillo es más de aquí, está más visto.

-Los ingleses tenían que ver el novillo ensogado.

-El foot-ball queda más moderno [1991: 67].

La presencia de las costumbres extranjeras no acaba en los recién nacidos deportes que con el paso del tiempo se convertirían en espectáculos de masas. Parodia igualmente Mingote el prestigio de los artículos extranjeros entre la clase media española. Consigue en esta ocasión un buen resultado sirviéndose de la enumeración masiva. El autor no hace más que parodiar los anuncios que eran habituales en los periódicos de entresiglos, del tipo del que sigue: «Os podéis librar del vicio de la borrachera gracias al remedio Coza (en polvo) de 76 Wadour Street, Londres, 201. Inglaterra» [1991:72]. Incluso algunas costumbres y usos nacionales entran en competencia con otros foráneos; por esa razón Hortensia le pregunta al conde si monta «a la española o la inglesa» [1991: 120].

A diferencia de Las palmeras... y Los revólveres..., la novela de Mingote tiene un final cerrado recogido en un «Epílogo». El narrador informa al lector del desenlace de los hechos que han ido presentándose a lo largo del relato así como de su propia identidad. Esa práctica es común asimismo en muchos de los relatos cortos que Mingote publicó en su libro De muerte natural [1993], cuentos que atesoran la técnica y el humor que su autor ha ido engrandeciendo con los años.

$\mathrm{Y}$ concluyo. En el panorama narrativo español de las dos primeras décadas de la dictadura franquista, la novela humorística de Mingote, y de otros autores contemporáneos suyos, dio al lector la posibilidad de zafarse tanto de la truculencia del relato tremendista como de la salmodia del realismo objetivo, obra de autores que seguían poniendo el dedo en la llaga 
de la guerra civil y sus consecuencias. A cambio se ofrecía una nueva mirada de la realidad contemplada en clave de humor del absurdo, arropado éste por la idea de que la libertad individual debía romper el caparazón del tópico, y por la confianza en que la cursilería de las consignas de la época podía ser conjurada por la inteligencia del ciudadano. Se defendía, en otro orden de cosas, la victoria de las pequeñas revoluciones individuales, frente a la adhesión a causas nobles perdidas de antemano. La vigencia de este humor en la obra posterior de Mingote, escrita ya en un contexto sociopolítico radicalmente opuesto al de la posguerra, corrobora la opinión de que toda sociedad debe permanecer avisada de que la peor dictadura es la autocomplacencia. 


\section{BIBLIOGRAFÍA CITADA}

ACEvedo, E. (1966), Teoría de la interpretación del humor español, Madrid, Editora Nacional.

Amorós, A. (1979), Introducción a la novela contemporánea, Madrid, Cátedra.

Baquero Goyanes, M. (1955), «La novela española de 1939 a 1953», Cuadernos Hispanoamericanos, 67, pp. 81-95.

Bergson, H. (1984), Le rire. Essai sur la signification du comique, en Oeuvres, textos anotados por A. Robinet, introd. de H. Gouhier, Presses Universitaires de France, París, pp. 383-485. Se publicó originalmente en la Revue de Paris, febrero-marzo 1899. Hay traducciones españolas: La risa, Buenos Aires, Losada, 1943; Valencia, Prometeo, 1950 y 1971 [que coincidió en el tiempo con la nonagésima séptima edición francesa de las Presses Universitaires de France, Paris, 1950]; Barcelona, Orbis, 1986; Madrid, Espasa Calpe, 1973 y 1986, etc.

Botín Polanco, A. (1951), Manifiesto del humorismo, Madrid, Revista de Occidente.

Burguera Nadal, Mª. L. (ed.) (1995), Mingote, obra escrita, Madrid, Ediplus.

- (1998), «El humorismo literario en la obra escrita de Antonio Mingote», en Actas del XII Congreso de la Asociación Internacional de Hispanistas, vol. V, ed. de D. W. Flitter, Birmingham, The University of Birmingham, pp. 48-56.

Campos, J. (1949), reseña a Las palmeras de cartón de Antonio Mingote, Punto, Madrid, 1-2, p. 9.

Castellet, J. Ma . (1963), «Veinte años de novela española (1942-1962)», Cuadernos Americanos, CXXVI.

FERNÁNDEZ FLÓREZ, W. (1979), «El humor en la literatura española» (Discurso de ingreso en la Real Academia Española), en Obras selectas, Barcelona, Carroggio, 1979, pp. 18-49.

GARCIA Fuentes, E. (1995), «La novela de humor en torno al 50. Las palmeras de cartón, de Antonio Mingote», en M. J. Ramos Ortega y Ana-Sofía Pérez Bustamante (eds.), La literatura española alrededor de 1950: panorama de una diversidad, Cádiz, Universidad, pp. 115-137.

Gómez DE la Serna, R. (1928), "Gravedad e importancia del humorismo», Revista de Occidente, LVI, pp. 348-360.

- (1931), «Humorismo», en Ismos, Madrid, Biblioteca Nueva [Madrid, Guadarrama, 1975, pp. 197-233]. 
González-Grano de Oro, E. (2004), La otra generación del 27. El Humor Nuevo español y La Codorniz primera, Madrid, Polifemo.

LlerA, J. A. (2001), «Poéticas del humor: desde el novecentismo hasta la época contemporánea», Revista de Literatura, LXIII, 126, pp. 461-476.

López Rubio, J. (1983): «La otra generación del 27», Discurso de ingreso en la R.A.E., Madrid, RAE.

Martinez Cachero, J. Mª (1945), Novelistas españoles de hoy, Oviedo, Sindicato Español Universitario.

- (1979a), «Novelistas jóvenes y panorama editorial en la década de los cuarenta», en Estudios ofrecidos a Emilio Alarcos, vol. IV, Oviedo, Universidad, pp. 479-494.

- (1979b), Historia de la novela española entre 1936 y 1975, Madrid, Castalia.

- (1983), «Más sobre la novela española en la década de los cuarenta: narrativa de humor», en Serta Philologica F. Lázaro Carreter, II, Madrid, Cátedra, pp. 339-346.

- (1997), La novela española entre 1939 y el fin de siglo: historia de una aventura, Madrid, Castalia.

MinuRa, M. (1989), Tres sombreros de copa. Maribel y la extraña familia, ed. del autor, Madrid, Castalia.

Mingote, A. (1948), Las palmeras de cartón, dibujos de Lorenzo Goñi, colección «El lagarto al sol», Madrid, Librería Clan.

- (1949), Ojos de esmeralda, Madrid, Saturnino Calleja, colección «El Elefante Blanco», serie policíaca. Bajo pseudónimo de Anthony Mask.

- (1953), Los revólveres hablan de sus cosas, Madrid, Prensa Española, colección «La novela del sábado».

- (1958), Las palmeras de cartón, cubierta de Mingote, Tetuán, Cremades.

- (1987), Las palmeras de cartón, Madrid, Ediciones El Observatorio.

- (1988), «Dos momentos del humor español: Madrid Cómico, La Codorniz». Discurso de recepción del Excmo. Sr. D. Antonio Mingote..., Madrid, RAE.

- (1991), Adelita en su desván, Barcelona, Planeta.

- (1993), De muerte natural, Madrid, Espasa Humor.

- (1996), Las palmeras de cartón, introducción de Rafael Conte, Madrid, Viamonte. 
- (1998) «LA Codorniz», en M. L. Burguera Nadal y S. Fortuño (EDS.), Vanguardia y humorismo: la otra generación del 27, Castellón, Universidad Jaime I, pp. 151-160.

- (2004) Los revólveres hablan de sus cosas, ed. de Catalina Luca de Tena, prólogo de J. L. Garci, y acotaciones cinematográficas de Oti Rodríguez Marchante, Madrid, Luca de Tena Ediciones.

Neville, E. (1955), «Ramón, el buque nodriza», Índice, 76, p. 5.

- (1969): «Sobre el humorismo», en Obras selectas, Madrid, Biblioteca Nueva, pp. 739.

Ríos Carratalá, J. A. (2005), «Miguel Mihura también fue a la guerra, aunque poco», en Miguel Mihura cumple un siglo. Actas de las Jornadas en homenaje al humorista y dramaturgo, ed. de R. Pérez Sierra, F. B. Pedraza y M. Rodríguez, Madrid, Comunidad de Madrid, pp. $99-115$.

Sobejano, G. (1975), Novela española de nuestro tiempo, Madrid, Prensa Española.

Soldevilla Durante, I. (2001), Historia de la novela española (19362000), Madrid, Cátedra.

TorriJos, J. Ma . (1989), «El otro grupo del 27: del humor al teatro», Religión y Cultura, xxxv, pp. 397-418.

VILAS, S. (1968), El humor y la novela española contemporánea, Madrid, Guadarrama.

Villanueva Nieto, C. (2002), Mingote, punto y aparte, Málaga, Grupo Editorial 33.

YNDURÁIN, F. (1952), «Novelas y novelistas españoles, 1936-1952», Rivista de Letterature Moderne, enero-marzo, pp. 279-284. 